\title{
Protein Kinase CK2, a Potential Therapeutic Target in Carcinoma Management
}

\author{
Haiwei Lian ${ }^{1}$, Min Su${ }^{1}$, Yijie Zhu ${ }^{1}$, Yun Zhou ${ }^{2}$, Shahid Hussain Soomro ${ }^{1}$, Hui Fu ${ }^{1,3 *}$
}

\begin{abstract}
The Protein kinase CK2 (formerly known as casein kinase 2) is a highly conserved serine/ threonine kinase overexpressed in various human carcinomas and its high expression often correlates with poor prognosis. CK2 protein is localized in the nucleus of many tumor cells and correlates with clinical features in many cases. Increased expression of CK2 in mice results in the development of various types of carcinomas (both solids and blood related tumors, such as (breast carcinoma, lymphoma, etc), which reveals its carcinogenic properties. CK2 plays essential roles in many key biological processes related to carcinoma, including cell apoptosis, DNA damage responses and cell cycle regulation. CK2 has become a potential anti-carcinoma target. Various CK2 inhibitors have been developed with anti-neoplastic properties against a variety of carcinomas. Some CK2 inhibitors have showed good results in in vitro and pre-clinical models, and have even entered in clinical trials. This article will review effects of CK2 and its inhibitors on common carcinomas in in vitro and pre-clinical studies.
\end{abstract}

Keywords: Protein kinase CK2- solid tumors- hematological tumors- CX-4945- CIBG-300

Asian Pac J Cancer Prev, 20 (1), 23-32

\section{Introduction}

Protein kinase CK2 is a highly conserved serine/ threonine kinase that is ubiquitously expressed in a variety of eukaryotic cells. CK2 kinase may act as a monomeric kinase alone or as a tetrameric complex, which consist of 2 catalytic subunits (CK2 $\alpha$ and/or CK2 $\alpha^{\prime}$ ) and 2 regulatory subunits CK2 $\beta$. Its catalytic part is encoded by two genes, CK2 $\alpha$ (CSNK2A1) and CK2 $\alpha^{\prime}$ (CSNK2A2). In mouse tissues, expression levels of CK2 $\alpha$ are higher than those of CK2 $\alpha^{\prime}$ (Xu et al., 1999b). A separate gene CSNK2B encodes the regulatory subunit $\mathrm{CK} 2 \beta$, which regulates the substrate specificity of CK2 kinase and enhances the catalytic subunit stability in the tetrameric complex of CK2 (Bibby et al., 2005). In addition, an intron less CK2 $\alpha$ pseudo-gene $(\mathrm{CK} 2 \alpha \mathrm{P})$ can be activated in mammalian cells and is, to some extent, associated with carcinomas (Wirkner et al., 1992; Ortega et al., 2014). Interestingly, CK2 subunits mutually regulate their protein expression levels. For example, inhibition of CK $2 \alpha$ can reduce CK2 $\beta$ expression or vice versa (Zhang et al., 2002; Olsen et al., 2010).

Protein kinases are the largest family among kinases. Protein kinases act on specific substrates and phosphorylate them to alter their activity. Protein kinase CK2 claims a diverse range of substrates. Researchers described that the number of CK2 substrates was 307 in 2003 (Meggio et al., 2003) and the number has increased greatly afterward. About one third of CK2 substrates are involved in gene expression and protein synthesis, including transcription factors, DNA/ RNA structural and translational elements. Many substrates are involved in signal pathways, the source of viruses, or crucial to the life cycle of viruses. A small number of CK2 substrates are classical metabolic enzymes. It is assumed that the CK2 monomeric enzyme is more conducive to the production of phospho-protein in eukaryotic cells than any other protein kinase. CK2 is widespread in eukaryotes and involved in almost all kind of key processes in the cells. It enhances cell proliferation (Pinna et al., 1997; Ahmed et al., 2000), cell growth (Litchfield, 2003), cell survival (Ahmed et al., 2002; Ahmad et al., 2008), changes cell morphology (Canton et al., 2006), increases cellular transformation (Seldin et al., 2005; Dominguez et al., 2009) and promotes angiogenesis (Kramerov et al., 2008; Montenarh, 2014). Thus CK2 plays a very important role in the growth and development of vertebrates.

There are two kinds of CK2 $\alpha$ genes in zebra fish (CK2 $\alpha$ and CK2 $\alpha$ ') and one kind of CK2 $\beta$ gene (Daniotti et al., 1994; Antonelli et al., 1996). The expression levels of CK2 $\alpha$ gene after 1 hour post fertilization (hpf) were higher than those after $24 \mathrm{hpf}$. There was no difference in the transcription levels of CK2 $\beta$ between 1 and $24 \mathrm{hpf}$. The formation of zebra fish gastrula (5-10

${ }^{1}$ Department of Human Anatomy, School of Basic Medical Sciences, ${ }^{2}$ Department of Gynaecology, Renmin Hospital, Wuhan University, Wuhan, Hubei, P.R. ${ }^{3}$ Shenzhen Institute of Wuhan University, Shenzhen, China. *For Correspondence: hueyfu@hotmail.com 
hpf), three-germ layered embryo, requires CK2. DMAT, a specific inhibitor of CK2, delays the gastrulation in zebrafish embryos (Finkielsztein et al., 2009). CK2 may inhibit the activity of PTEN by phosphorylation during gastrulation, thus impairs cell motility associated with gastrulation (Finkielsztein and Kelly, 2009). In addition, CK2 also affects angiogenesis in zebrafish embryos. Emodin inhibits CK2 and suppresses the proliferation and migration of endothelial cells, the formation of endothelial cell tube and vascularization (Crawford et al., 2011).

\section{CK2 and embryo development}

In mouse embryos, the activity of CK2 peaks at 12 days of pregnancy days 12(E12) and decreases at birth (Schneider et al., 1986). Mouse, mRNA and protein of CK $2 \alpha$ and CK2 $\beta$ have different temporal and spatial expression patterns in different organs from day E10.5 to E18.5 (Mestres et al., 1994). CK2 $\alpha$ and CK2 $\beta$ are enriched in neuroepithelial and epithelial cells, with high levels in epithelial cells at E10.5 and neuroepithelial cells at E11.5 (Mestres et al., 1994). CK2 is also expressed in heart, skeletal muscle, connective tissues and cartilage (Mestres et al., 1994; Lou et al., 2008). The deletion of CK2 $\alpha$ results in the death of mice at E11 while loss of CK2 $\beta$ results in early death of mice at E6.5 (Buchou et al., 2003). Mice can survive without CK2 $\alpha$, but male mice become infertile (Xu et al., 1999a).

\section{CK2 and tumor}

The expression of CK2 is often found aberrant in carcinoma cells. Research data have shown that overexpression of CK2 in mice induces carcinoma, suggesting CK2 plays an important role in the carcinoma pathogenesis (Dominguez et al., 2005; Seldin et al., 2005; Dominguez et al., 2009; Ruzzene et al., 2010; Zhang et al., 2015). The ability of protein kinase CK2 to promote tumorigenesis, to a large extent, depends upon, how it modulates key signaling pathways, which may be different among various carcinomas. CK2 regulates a number of signaling cascades such as Wnt (Dominguez et al., 2004; Dominguez et al., 2005), Hedgehog (Jia et al., 2010), NF- $\kappa$ B (Dominguez et al., 2009), JAK / STAT (Zheng et al., 2011), and PTEN / PI3K / Akt-PKB (Torres et al., 2001; Miller et al., 2002; Di Maira et al., 2005; Park et al., 2013) signaling pathways. Dysregulation of these signaling pathways can lead to tumorigenesis. CK2 promotes tumorigenesis in a variety of ways, such as enhancing the stability of MYC proto-oncogene (Channavajhala et al., 2002), activation of NF- $\mathrm{B}$ (anti-apoptotic factor) (Romieu-Mourez et al., 2002), inhibition of DNA repair and inhibition of the tumor suppressor phosphatase, PTEN (Torres and Pulido, 2001; Miller et al., 2002).

Various CK2 chemical inhibitors with good cell permeability have been developed. The most commonly studied inhibitors are CX-4945 (Siddiqui-Jain et al., 2010), CIGB-300 (Perea et al., 2008), TBB (Sarno et al., 2001), DMAT (Pagano et al., 2004), Quinalizarin (Cozza et al., 2009), hematein (Hung et al., 2009), TBCA (Pagano et al., 2007), DRB (Zandomeni et al., 1986), apigenin (Hagiwara et al., 1988), Emodin (Yim et al., 1999) and TF (Gotz et al., 2012). Among them, CX-4945 and CIGB-300 have been enrolled in clinical trials to test their anti-tumor effects and toxic side effects in human.

\subsection{The expression and role of CK2 in solid tumors}

Expression of CK2 mRNA and protein is variable in different tumors. mRNA and protein levels of CK2 are up-regulated in many carcinomas. In some cases, an increase in CK2 protein levels was detected with no changes in mRNA levels (Tawfic et al., 2001). We have noticed that not all published data support the notion that overexpression of CK2 is driver for tumorigenesis and associated with poor prognosis. CK2 gene expression is down-regulated in some tumors (e.g, CK $2 \alpha^{\prime}$ is down-regulated in breast, ovarian and pancreatic carcinomas) and up-regulation of CK2 gene in some tumors correlates with increased survival time (e.g, adenocarcinoma of lungs) (Wirkner et al., 1992; Ortega et al., 2014). Nonetheless in general, up-regulation of CK2 mRNA and / or protein is associated with poor prognosis.

The overexpression of CK2 is associated with poor prognosis of many common solid tumors, including those associated with the chronic exposure to carcinogen such as head and neck carcinomas, non-small cell lung carcinoma, urinary bladder carcinoma or mesothelioma. CK2 is also involved in the pathogenesis of gastrointestinal malignancies, including hepatobiliary carcinoma, esophageal carcinoma and gastric carcinoma, and other types of tumors such as renal carcinoma, cervical carcinoma and glioblastoma multiforme. Table 1 summarizes expression levels of CK2 in common malignant solid tumors and its effects on tumor biological behavior. When there is no publicly published data, expression levels of $\mathrm{CK} 2$ are unlabeled in that type of tumors.

\subsubsection{The role of CK2 inhibitors in solid tumors}

Based on the abnormal expression of CK2 in most of malignant solid tumors, it seems possible to treat those tumors with a CK2 inhibitor. In most malignancies, it has been demonstrated that inhibition of CK2 can affect the biological behavior of tumor cells in both in vivo and in vitro experiments. CK2 inhibitors reduce the migration and invasion of human adenocarcinoma and non-small cell lung carcinoma (NSCLC) cells by down-regulating the transcriptional expression and activity of MMP-2 via the ERK pathway ( $\mathrm{Ku}$ et al., 2013). The use of CK2 inhibitors (e.g TBCA, TBB and hematein) along with radiotherapy significantly reduced the number of cells in four different types of large cell lung carcinoma (LCLC) and adenocarcinoma cells compared with single drug therapy or radiotherapy alone (Lin et al., 2011). Quinalizarin inhibits the viability of adenocarcinoma cells with EGFR mutations more significantly than those without EGFR mutations (Zhou et al., 2015). The inhibitor hematein reduced lung adenocarcinoma cell colony formation, phosphorylated AKT levels, and increased PARP fragmentation (Hung et al., 2010). In xenograft models of lung adenocarcinoma, Hematein was also found suppressing tumor growth (Hung et al., 2013). 
Table 1. CK2 Expression Level in Common Malignant Solid Tumors and Its Influence on Biological Behavior of Carcinoma

\begin{tabular}{|c|c|c|}
\hline Tumor Type & Expression Level of CK2 & Affected Biological Behavior \\
\hline $\begin{array}{l}\text { Lung carcinoma (Daya-Makin et al., 1994; } \\
\text { Yaylim et al., 2002; P et al., 2004; Hung et al., } \\
\text { 2010; Ortega et al., 2014) }\end{array}$ & $\begin{array}{c}\mathrm{CK} 2 \alpha, \mathrm{CK} 2 \alpha^{\prime}, \mathrm{CK} 2 \beta \text { and } \\
\mathrm{CK} 2 \alpha \mathrm{P} \uparrow^{*}\end{array}$ & $\begin{array}{l}\text { Cell proliferation, survival, migration and } \\
\text { invasion, maintenance of stem cell }\end{array}$ \\
\hline $\begin{array}{l}\text { Mammary carcinoma (Gray et al., 2014; Ortega } \\
\text { et al., 2014; Kren et al., 2015; Bae et al., 2016) }\end{array}$ & $\mathrm{CK} 2 \alpha \uparrow, \mathrm{CK} 2 \beta \uparrow, \mathrm{CK} 2 \alpha^{\prime} \downarrow^{*}$ & $\begin{array}{l}\text { Cell morphology, proliferation (anchorage- } \\
\text { independent proliferation), migration and } \\
\text { invasion }\end{array}$ \\
\hline Urothelialcarcinoma (Shimada et al., 2011) & $\mathrm{CK} 2 \alpha \uparrow$ & Cell cycle arrest, metastasis \\
\hline $\begin{array}{l}\text { Head and neck carcinoma } \\
\text { (Gapany et al., 1995; Faust et al., 1996; Heriche } \\
\text { et al., 1998; Faust et al., 2000; Bian et al., 2015) }\end{array}$ & $\mathrm{CK} 2 \alpha, \mathrm{CK} 2 \alpha$, and $\mathrm{CK} 2 \beta \uparrow$ & $\begin{array}{l}\text { Cell cycle regulation, proliferation, metastasis, } \\
\text { tumor stem cell-like cell maintenance }\end{array}$ \\
\hline Mesothelioma (Quotti Tubi et al., 2013) & $\mathrm{CK} 2 \alpha \uparrow$ & Cell Proliferation \\
\hline $\begin{array}{l}\text { Hepatocellular carcinoma (Wu et al., 2014; } \\
\text { Zhang et al., 2015) }\end{array}$ & $\mathrm{CK} 2 \alpha, \mathrm{CK} 2 \alpha^{\prime} \uparrow$ & $\begin{array}{l}\text { Cell proliferation and colony formation, cell } \\
\text { cycle distribution, apoptosis, migration and } \\
\text { invasion }\end{array}$ \\
\hline Gastric carcinoma (Lee et al., 2014) & $\mathrm{CK} 2 \alpha \uparrow$ & Cell proliferation, migration and apoptosis \\
\hline Esophageal carcinoma (Yoo et al., 2012) & $\mathrm{CK} 2 \alpha \uparrow$ & Invasiveness, cell proliferation and metastasis \\
\hline Cholangiocarcinoma (Zhou et al., 2014) & $\mathrm{CK} 2 \beta \uparrow, \mathrm{CK} 2 \alpha \uparrow$ & \\
\hline $\begin{array}{l}\text { Colorectal carcinoma (Lin et al., 2010; Zou et al., } \\
\text { 2011; Ortega et al., 2014) }\end{array}$ & $\mathrm{CK} 2 \alpha \uparrow$ & $\begin{array}{l}\text { Cell proliferation, cell cycle distribution, cell } \\
\text { motility and invasiveness }\end{array}$ \\
\hline $\begin{array}{l}\text { Pancreatic carcinoma (Hamacher et al., 2007; } \\
\text { Giroux et al., 2009; Guerra et al., 2015) }\end{array}$ & $\mathrm{CK} 2 \alpha^{\prime} \uparrow$ & Apoptosis \\
\hline $\begin{array}{l}\text { Cervical carcinoma (Perera et al., 2014; Liu et } \\
\text { al., 2015) }\end{array}$ & Not yet clear & $\begin{array}{l}\text { Cell proliferation, tumor stem cell } \\
\text { maintenance }\end{array}$ \\
\hline $\begin{array}{l}\text { Glioblastoma (Dixit et al., 2012; Zheng et al., } \\
\text { 2013; Mandal et al., 2014; Nitta et al., 2015) }\end{array}$ & $\mathrm{CK} 2 \alpha, \mathrm{CK} 2 \alpha^{\prime} \uparrow$ & $\begin{array}{l}\text { Proliferation, apoptosis, cell cycle, adhesion, } \\
\text { migration and molony formation, autophagy, } \\
\text { stem cell phenotype maintenance }\end{array}$ \\
\hline Melanoma (Zhou et al., 2016) & $\mathrm{CK} 2 \alpha \uparrow$ & Cell proliferation \\
\hline $\begin{array}{l}\text { Ovarian carcinoma (Pathak et al., 2015; Tang et } \\
\text { al., 2015) }\end{array}$ & $\mathrm{CK} 2 \alpha \uparrow$ & Tumor stem cell maintenance \\
\hline Prostatic carcinoma (Yoo et al., 2012) & $\mathrm{CK} 2 \alpha \uparrow$ & Apoptosis, invasion \\
\hline Renal cell carcinoma (Stalter et al., 1994) & $\mathrm{CK} 2 \alpha, \mathrm{CK} 2 \alpha^{\prime}$ and $\mathrm{CK} 2 \beta \uparrow$ & Cell survival \\
\hline
\end{tabular}

\section{Head and neck tumors}

In head and neck squamous cell carcinoma (HNSCC), antisense CK2 $\alpha$ decreased the number of cells (Faust et al., 2000; Brown et al., 2010) and induced apoptosis (Wang et al., 2001; Brown et al., 2010). Similarly, antisense CK2 $\beta$ also induced apoptosis (Faust et al., 2000; Brown et al., 2010). Knock-down of CK2 $\alpha$, CK2 $\alpha$ ' or CK2 $\beta$ alone left the HNSCC cell arrested in the G0 / G1 phase. Similarly, CX-4945 reduced the number of HNSCC cells, induced cell cycle arrested in S or G2 / $\mathrm{M}$ phases, and increased apoptosis (Bian et al., 2015). CK2 inhibitors have reduced tumor load in preclinical models of head and neck carcinomas. In HNSCC xenograft tumor models (lingual carcinoma, hypopharyngeal and laryngeal carcinoma), CK2 inhibitor (nano-capsules containing RNAi-CK2 $\alpha / \alpha$ ') significantly reduced tumor volume, decreased the number of metastases and increased the survival time of mice (Unger et al., 2014). In addition, tumors of mice treated with CK $2 \alpha / \alpha^{\prime}$-RNAi showed reduced staining of proliferating proteins (such as cyclin D1) and up-regulation of tumor suppressor genes (such as P53) compared with tumors of control mice (Brown et al., 2010).

\section{Glioblastoma multiforme}

Preclinical xeno-grafted glioblastoma multiforme (GBM) models demonstrated that various CK2 inhibitors were effective in inhibiting tumors growth and enhancing survival in mice (Prudent et al., 2010; Moucadel et al., 2011; Zheng et al., 2013; Nitta et al., 2015; Chou et al., 
2016). Inhibitors also decreased the activation of AKT, c-MYC, STAT-3, NF- $\kappa \mathrm{B}$, and the expression of EGFR, indicating that $\mathrm{CK} 2$ regulates various signaling pathways responsible for proliferation and survival (Zheng et al., 2013; Chou et al., 2016). In addition, silencing of CK2 alone or with EGFR increased tumor necrosis and mouse survival rate (Chou et al., 2016). Therefore, for patients with GBM who have undergone surgical resection plus radiotherapy combined with temozolomide adjuvant chemotherapy, the use of CK2 inhibitors may, to a certain extent, prevent tumor recurrence.

\section{Hepatocellular carcinoma}

In hepatocellular carcinoma (HCC), DMAT and CK2 $\alpha$ shRNAs inhibited the growth of tumors in a mouse xenograft model of liver carcinoma (Sass et al., 2011; Zhang et al., 2015). DMAT acts by reducing tumor cell proliferation with no effects on cell survival nor angiogenesis, and more importantly with no liver damage, through a mechanism that is mediated by the reduction of NF- $\kappa \mathrm{B}$ and activation of Wnt / $\beta$-catenin signaling pathways (Sass et al., 2011). In addition, CK2 inhibitors also potentiated the efficacy of chemotherapeutic agents (5-fluorouracil, doxorubicin, or sorafenib) and helped in preventing the spread of HCC (Kim et al., 2008; Sass et al., 2011). These results indicated that CK2 inhibitors can effectively treat liver carcinomas as single or along with other remedies.

\section{Pancreatic carcinoma}

In mouse xeno-grafted pancreatic carcinoma models CX-4945 inhibited the tumor growth and reduced p21 staining (Siddiqui-Jain et al., 2010). In addition, intra-peritoneal injection of O-methyl-modified CK $2 \alpha$ siRNA resulted in a significant decrease in tumor volume and increased apoptosis of pancreatic carcinoma in mice (Giroux et al., 2009). The use of CK2 $\alpha$ siRNA in combination with PAK7 and / or MAP3K7 siRNA significantly reduced tumor volume (Giroux et al., 2009). Above treatments did not affect the body weight of mice. These data suggested that CK2 inhibitors can be used as an effective treatment for pancreatic carcinoma.

\section{Cervical carcinoma}

Apigenin inhibited the formation and self-renewal of sphere-forming cells (SFCs) of HeLa cells in cervical carcinomas, whereas overexpression of CK2 $\alpha$ conversely increased their capacity of self-renewal (Liu et al., 2015). CK2 inhibitor, CIGB-300 also inhibited cervical carcinoma cell proliferation and tumor growth in a mouse xeno-graft model even after treatment cessation (Siddiqui-Jain et al., 2010; Perera et al., 2014). Further, CIGB-300 had a synergistic effect with paclitaxel and doxorubicin and had an additive effect with cisplatin (CDDP). In combination with cisplatin, it could significantly slow the tumor growth and increase the survival of mouse (Perera et al., 2014).

CIGB-300 has also entered clinical trials to verify its anti-tumor effects on cervical carcinoma. In this clinical trial, 31 female patients with cervical carcinoma underwent CIGB-300 treatment. Drug was administered sequentially with increasing dosage for consecutive 5 days. Adverse effects were minimum even with the highest dose, and tumors were significantly reduced in $75 \%$ of the patients. Strikingly, $19 \%$ of patients had complete recovery (histologically proven) and $48 \%$ of patients became negative for HPV DNA at the end of the trial (Solares et al., 2009). After one year follow-up, there was no recurrence and no adverse event observed. Moreover, among treated patients, four were pregnant and two of whom were infertile before the intervention (Solares et al., 2009). Pharmacokinetic studies have provided the basis for CIGB-300's treatment in Phase II clinical trials (Sarduy et al., 2015). Therefore, human body can tolerate the inhibition of CK2. CK2 inhibition alone or with other chemotherapeutic drugs are promising for the treatment of cervical carcinoma (Liu et al., 2015). Another open clinical trial is currently undergoing in Argentina. Researchers use CIGB-300 for treating squamous cell carcinoma on, IIA and IIB FIGO stage patients with cervical adenocarcinoma, combined with external radiotherapy, intracavitary brachytherapy and weekly systemic treatment with cisplatin (trial number: NCT01639625).

\section{Ovarian carcinoma}

CX-4945, cisplatin and gemcitabine synergistically increased the apoptosis of A2780 tumors cell (Ovarian carcinoma cell line) with wild-type p53 while there was no change in the apoptosis of p53 null SKOV-3 cells (Siddiqui-Jain et al., 2012). The combination of CX-4945 with dasatinib (tyrosine kinase inhibitor) promoted apoptosis in an epithelial ovarian carcinoma cells (Pathak et al., 2015). In a xeno-grafted model (A2780 cells), the survival time of mice treated with CX-4945 along with 3 other drugs (cisplatin, carboplatin, and gemcitabine) was double to that of untreated control. Interestingly, carboplatin has a synergistic effect with CX-4945, whereas cisplatin and gemcitabine have additive effects on the inhibition of tumor growth. Therefore, CK2 inhibitors can be used to treat advanced ovarian carcinomas.

\section{Prostate carcinoma}

Proliferation of prostate carcinoma cells can be reduced by CK2 inhibitors (TF, TBB, DMAT, TBCA siRNA, apigenin, and KI-CK2 $\alpha$ ) (Wang et al., 2005; Schneider et al., 2009; Gotz et al., 2012; Trembley et al., 2012; Yao et al., 2012; Trembley et al., 2014), while the apoptosis was increased (Wang et al., 2008; Schneider et al., 2009; Hessenauer et al., 2011; Pierre et al., 2011; Gotz et al., 2012; Yao et al., 2012; Qaiser et al., 2014). CX-4945, TBCA and apigenin induced cell cycle arrested at the G2 / M phase (Pierre et al., 2011; Yao et al., 2012). Furthermore, DMAT and CK2 $\alpha$ / $\alpha$ 'siRNAs were capsulated and were found to specifically reduce the proliferation of the prostate carcinoma cell line (PC3-LN4) but not the benign cell line (BPH-1) (Trembley et al., 2012). CK $2 \alpha / \alpha$ ' siRNAs also affected C4-2 prostate carcinoma cell line but not normal prostatic epithelial cell line (Funfschilling et al.; Trembley et al., 2012). The inhibition of CK2 can reduce tumor load in xeno-grafted mouse models. CK2 $\alpha / \alpha$ 'siRNA, RNAi (Ahmed et al., 2016) and CX-4945(Pierre et al., 2011) 
reduced tumor volume in metastatic $\mathrm{PC}$-3-derived xeno-grafted models. DMAT decreases the proliferation of PC3-LN4 cell-derived xeno-grafted tumors and decreased protein levels of CK2 $\alpha$ and CK2 $\alpha$ ' (Trembley et al., 2014).

\section{Breast carcinoma}

In preclinical studies of breast carcinoma, CX-4945 reduced the growth of tumors in a mouse model of orthotopic xeno-transplantation of breast carcinoma with no body weight loss and no significant toxicity (Siddiqui-Jain et al., 2010). Inhibition of CK2 can also enhance the sensitivity of breast carcinoma to antitumor drugs. DMAT effectively reduced the number of cells, increased apoptosis and altered cell morphology in breast carcinoma cells resistant to tamoxifen (Yde et al., 2007). CK2 inhibitors are potential therapeutic agents for triple-negative and estrogen-tolerant breast carcinoma.

\subsubsection{The combination of CK2 inhibitors and other antitumor drugs}

CK2 plays a role in tumor chemotherapeutic drug resistance. CK2 has been considered to mediate resistance to cisplatin in gastric carcinoma cell, as increased levels of $\mathrm{CK} 2 \alpha$ protein have been observed in these types of carcinomas (Xu et al., 2014). In addition, CK2 protected colon carcinoma cells from TRAIL (TNF related apoptosis inducing ligand) induced apoptosis. Reciprocally inhibition of CK2 phosphorylation by DRB resulted in increased cells apoptosis induced by TRAIL in colon carcinoma cells. shRNA interference with CK2 $\alpha$ also increased the sensitivity of human colorectal adenocarcinoma cells to TRAIL (Izeradjene et al., 2005).

Perera et al., (2014) have observed the synergistic interaction between CK2 inhibitor CIGB-300 and other chemotherapeutic drugs, in the preclinical tumor models of lung carcinoma and cervical carcinoma (Liu et al., 2015). They used Cisplatin (alkylation), 5- fluorouracil (DNA/RNA antimetabolite), Paclitaxel (anti-mitosis), and Doxorubicin (anti topoisomerase II) to treat lung carcinoma and cervical carcinoma cells. Results showed excellent synergistic / additive effects of cisplatin and paclitaxel with CIGB-300, according to the combination and dose reduction index. Paclitaxel showed the strongest synergistic effect in combination with CIGB-300 in $\mathrm{SiHa}$ and NCI-H125 cell lines and exhibited the same inhibitory effect on cell proliferation with reduced dose (1/5 of normal CIGB-300 dosage). These findings provided a theoretical basis for the clinical combination of anti-CK2 (CIGB-300) and other antitumor drugs, and suggested that platinum and taxane can be used as anti-cancer drugs with good prospect. Similarly, CX-4945 has been studied in combination with erlotinib (an EGFR tyrosine kinase inhibitor) for the treatment of advanced non-small cell lung carcinoma. Bliesath et al., (2012) investigated the combined effect of CX-4945 and erlotinib in non-small cell lung carcinoma and squamous cell carcinoma in both, in vitro and in vivo. They found significant inhibition of the PI3K-Akt-mTOR signaling pathway and tumor growth arrest with the combination treatment. Additionally, they noticed the decreased cell proliferation and increased cell apoptosis after combination treatment. In conclusion, these data suggested that CK2 can be used as an effective pharmacological target for combination treatment of carcinomas. Studies also emphasized on further exploration of combined effects of CX-4945 and EGFR targeting agents (Bliesath et al., 2012).

The combined use of CX-4945 with gemcitabine and cisplatin in the treatment of cholangiocarcinoma is currently undergoing phase I / II clinical trial. CX-4945 can inhibit DNA repair and is particularly effective in combination with DNA damaging drugs such as cisplatin. The purpose of this clinical study is to determine the maximum-tolerated dose (MTD) of drugs and compare the antitumor activity of standard gemcitabine / cisplatin with that of the combination of three drugs. This project has been conducted at a number of central research institutes in the United States, South Korea and Taiwan. The completion date of the study was December 2017 (test number: NCT02108282). No report has been published yet.

\subsection{CK2 and Hematological tumor}

Hematological tumors are mostly liquid tumors. Their cells exist in blood circulation, and can invade any hematopoietic organ and tissue. The treatments of lymphoma and myeloma have been greatly improved. CK2 inhibitors may be of little use in some cases. But there are still other reasons for their usage, especially in cases of acute leukemia.

\subsubsection{Non-Hodgkin's lymphoma (NHL)}

Recently multiple drugs are available for the treatment of NHL, but there is still a strong need for new treatment with better efficacy and less adverse effects. A recently published study showed that levels of CK2 $\alpha$ and CK2 $\beta$ protein increased in Burkitt's lymphoma, DLBCL, follicular lymphoma, and lymphoma cell lines (Pizzi et al., 2015). CK2 inhibitor CX-4945 can induce a dose-dependent increased apoptosis in Burkitt's lymphoma and DLBCL cells (Pizzi et al., 2015), while CX-4945 does not affect normal peripheral blood mononuclear cells. In animal models, the increased expression of CK2 $2 \alpha$ in lymphocytes of transgenic mice led to the occurrence of T cell lymphoma (Seldin, 1995; Seldin et al., 1995; Channavajhala and Seldin, 2002). These data suggested that the development of CK2 inhibitors is still of great significance for the treatment of NHL.

\subsubsection{Multiple myeloma}

Although treatment options for multiple myeloma (MM) have increased rapidly in recent years, but in most cases the final results are deterioration or death. Therefore, there is still a need to explore new treatment options for better management. CK2 kinase activity and CK2 $\alpha$ protein levels increase in bone marrow cells of multiple myeloma patients (Piazza et al., 2006; Manni et al., 2013). Similarly, CK $2 \alpha$ and CK2 $\beta$ staining increased significantly in multiple myeloma tissue samples (Manni et al., 2013). Inhibition of CK2 by IQA, TBB, apigenin and TBB derivative $\mathrm{K} 27$ (2- amino -4,5,6,7- four bromo -1H- benzimidazole) (Zhao et al., 2011) can reduce the viability and increase the apoptosis of myeloma cells. 
This suggested that CK2 $\alpha$ plays a role in the survival of myeloma cells (Piazza et al., 2006; Manni et al., 2013; Piazza et al., 2013).

CK2 inhibitors induced the impairment of NF- $\kappa$ B-dependent transcriptional activity (Piazza et al., 2006) and also down regulated endoplasmic reticulum (ER) stress response, resulted in increased apoptosis (Manni et al., 2013). This is because myeloma cells produced abnormally excessive quantity of antibodies. ER- stress/ unfolded protein response is essential for the survival of myeloma cells. Existing studies have shown that CK2 inhibitors act synergistically with the conventional chemotherapeutic drug, Melphalan, to increase cytotoxicity (Piazza et al., 2006). CK2 inhibitors combined with geldanamycin (an anti-cancer drug) also have a cumulative effect and can increase the apoptosis of cells (Manni et al., 2013). Therefore, CK2 inhibitors can enhance the sensitivity of myeloma to chemotherapy and reduce its required dosage (Piazza et al., 2006). All above mentioned studies indicated that CK2 might represent a potential target in MM therapy.

\subsubsection{Leukemia}

CK2 plays an important role in acute myeloid leukemia (AML), acute lymphoblastic leukemia (ALL) and chronic lymphocytic leukemia (CLL). The activity of CK2 and its protein levels are up-regulated in primary B-ALL, T-ALL, AML, CLL cells (Martins et al., 2010; Gomes et al., 2014; Song et al., 2015). In AML patients, high CK2 $\alpha$ protein levels are the predictor of the overall survival rate (Kim et al., 2007). CK2 participates in multiple blood tumor related signal transduction pathways, including PI3K/AKT/PTEN, JAK/STAT, NF- $\kappa B$ and others (Piazza et al., 2012). PI3K/AKT/PTEN cascade regulation is crucial for survival and proliferation of ALL, CLL, and AML tumor cells. In chronic myeloid disease (CMD) and multiple myeloma (MM), CK2 regulates the activation of JAK / STAT, downstream of cytokine / growth factor signaling. CK2 mediates I $\mathrm{B} \alpha$ phosphorylation (Located in the PEST domain) and causes the latter to be degraded by the proteasomal pathway. After the degradation of $\mathrm{I} \kappa \mathrm{B} \alpha, \mathrm{NF}-\kappa \mathrm{B}$ p65 enters into the nucleus, where CK2 mediates Ser529 phosphorylation of NF- $\kappa$ B p 65 to activate $\mathrm{NF}-\kappa \mathrm{B}$ pathway. This pathway is very important for the survival of CLL and MM cells as it provides the resistance to chemotherapeutic drugs.

In AML cell lines, overexpression of CK $2 \alpha$ leads to fewer cells in the G0 / G1 phase, whereas CK2 inhibition by CX-4945, K27, apigenin or CK $2 \alpha$ siRNA led to increased apoptosis (Kim et al., 2007; Quotti Tubi et al., 2013). It has been reported that normal bone marrow cells are hardly affected by apigenin (Kim et al., 2007). Furthermore, the use of CK2 inhibitors or CK2 $\alpha / \beta$ siRNA can sensitize AML cells to daunorubicin (AML chemotherapeutics) (Quotti Tubi et al., 2013).

In CLL, CK2 inhibition by CX-4945, DRB and TBB resulted in decreased cell viability without affecting normal T and B cells (Martins et al., 2010; Martins et al., 2014). Similar to ALL, primary CLL cells also showed up-regulation of phosphorylated PTEN. Knockdown or inhibition of CK2 increased expression levels of phosphorylated PTEN and PTEN (Martins et al., 2010). The CK2 inhibitor CIGB-300 also promoted the PTEN activation in CLL cells and terminated PI3K signaling pathway. Therefore, CIGB-300 decreases cell viability and proliferation in CLL cell lines, enhances apoptosis in primary leukemia cells, and showed anti-cancer activity in a human CLL xenograft mouse model (Martins et al., 2014).

In B-ALL cells, CX-4945 mediated inhibition of CK2 increased apoptosis in B-ALL cell lines and primary B-ALL cells but did not affect apoptosis in normal primary myeloid cells (Gomes et al., 2014). CX-4945 inhibited CK2-induced cell proliferation (Gowda et al., 2017). There are two possible mechanisms by which CX-4945 inhibits B-ALL: lowering levels of both total PTEN and phosphorylated PTEN (Gomes et al., 2014), and decreasing the phosphorylation of Ikaros, a tumor suppressor, thus restore the anti-leukemic function of Ikaros (Gowda et al., 2017). It is noteworthy that in both xenograft models of B-ALL cells and cell lines, CX-4945 inhibited leukemic cell growth and increased mouse survival (Gowda et al., 2017).

In T-ALL, the CK2 inhibitors CX-4945, TBB and DRB reduced primary T-ALL cell viability without affecting normal T cells (Silva et al., 2008; Buontempo et al., 2014). CX-4945 deterred tumor growth in T-ALL xenograft models (Buontempo et al., 2014). CK2 is overexpressed in T-ALL cell lines and is related to the increased activity of NOTCH1 and MYC. CX-4945 exerted pro-apoptotic effects on T-ALL cell lines and also promoted proteasomal degradation of NOTCH1 in cells and decreased MYC transcription. Overexpression of $\mathrm{CK} 2 \alpha$ in primary T-ALL cells correlated with PTEN phosphorylation, and inhibition of CK2 resulted in an increase in PTEN activity, therefore decreasing Akt phosphorylation (Kim et al., 2007; Silva et al., 2008; Martins et al., 2010; Piazza et al., 2012; Buontempo et al., 2014; Martins et al., 2014; Gowda et al., 2017). A recent study of CK2 in T-ALL showed that inhibition of CK2 induced apoptosis of T-ALL cells by regulating the endoplasmic reticulum stress (ER stress) / unfolded protein response (UPR) signaling pathway. CX-4945 down-regulated PI3K / Akt / mTOR signaling pathway, and might be effective in treating T-ALL diseases (Buontempo et al., 2014).

In conclusion, CK2 is overexpressed in many carcinomas and often associated with poor prognosis (but not in all cases). CK2 has been used as a diagnostic and prognostic marker for certain malignancies such as prostate carcinoma (Ortega et al., 2014; Qaiser et al., 2016). Further research about CK2 activity levels of all three CK2 subunits and their localizations may explore greater potential of CK2 as a diagnostic and prognostic marker. The mechanism of the increased CK2 RNA and protein levels in most carcinoma types is still unknown, while changes in gene dosage, epigenetic and post-translational regulation have been proposed. In some carcinomas the activity of CK2 is differentially displayed without changes in expression levels of CK $2 \alpha$ / $\alpha$ ' (Trembley et al., 2012; Yoo et al., 2012), suggesting the existence of additional post-translational regulatory 
mechanisms. CK2 protein is localized in nuclei of many tumor cells and correlates with clinical features in some cases. This suggests that the phosphorylation of target proteins in the nucleus is an importance step for the CK2 function in carcinoma. However, we know little about CK2 nuclear targets.

CK2 has become a potential anti-carcinoma target. It has been studied in various tumors include lung carcinoma, head and neck carcinoma, cholangiocarcinoma, cervical carcinoma and multiple myeloma, etc. CK2 inhibitors are highly effective against solid tumors and in combination with other therapies for hematological malignancies. Among them, CIGB-300 is well tolerated in clinical trials of cervical carcinoma. CX-4945 is also well tolerated in Phase I trials conducted at the MD. Anderson Carcinoma Center in the United States, involving a variety of patients with advanced solid tumors and multiple myeloma. These two inhibitors can be used as a single agent for treatment, just as other signal transduction inhibitors in some carcinomas. They can also be used in association with radiotherapy or in combination with other therapies such as immunotherapy and other drugs such as JQ1. Combination therapy displays several advantages as it can enhance anti-proliferative effects, help to overcome the drug resistance and reduce the drug dosage which leads to fewer side effects.

\section{Funding Source}

The fundamental research fund for Shenzhen Science and Technology, research grant. Grant number: JCY20160531193951630

\section{References}

Ahmad KA, Wang G, Unger G, et al (2008). Protein kinase CK2--a key suppressor of apoptosis. Adv Enzyme Regul, 48, 179-87.

Ahmed K, Davis AT, Wang H, et al (2000). Significance of protein kinase CK2 nuclear signaling in neoplasia. $J$ Cell Biochem Suppl, 35, 130-5.

Ahmed K, Gerber DA, Cochet C (2002). Joining the cell survival squad: an emerging role for protein kinase CK2. Trends Cell Biol, 12, 226-30.

Ahmed K, Kren BT, Abedin MJ, et al (2016). CK2 targeted RNAi therapeutic delivered via malignant cell-directed tenfibgen nanocapsule: dose and molecular mechanisms of response in xenograft prostate tumors. Oncotarget, 7, 61789-805.

Antonelli M, Daniotti JL, Rojo D, et al (1996). Cloning, expression and properties of the alpha' subunit of casein kinase 2 from zebrafish (Danio rerio). Eur J Biochem, 241, 272-9.

Bae JS, Park SH, Jamiyandorj U, et al (2016). CK2alpha/ CSNK2A1 phosphorylates SIRT6 and is involved in the progression of breast carcinoma and predicts shorter survival of diagnosed patients. Am J Pathol, 186, 3297-315.

Bian Y, Han J, Kannabiran V, et al (2015). MEK inhibitor PD-0325901 overcomes resistance to CK2 inhibitor CX-4945 and exhibits anti-tumor activity in head and neck cancer. Int J Biol Sci, 11, 411-22.

Bibby AC, Litchfield DW (2005). The multiple personalities of the regulatory subunit of protein kinase CK2: CK2 dependent and CK2 independent roles reveal a secret identity for CK2beta. Int J Biol Sci, 1, 67-79.
Bliesath J, Huser N, Omori M, et al (2012). Combined inhibition of EGFR and CK2 augments the attenuation of PI3K-Akt-mTOR signaling and the killing of cancer cells. Cancer Lett, 322, 113-8.

Brown MS, Diallo OT, Hu M, et al (2010). CK2 modulation of NF-kappaB, TP53, and the malignant phenotype in head and neck cancer by anti-CK2 oligonucleotides in vitro or in vivo via sub-50-nm nanocapsules. Clin Cancer Res, 16, 2295-307.

Buchou T, Vernet M, Blond O, et al (2003). Disruption of the regulatory beta subunit of protein kinase CK2 in mice leads to a cell-autonomous defect and early embryonic lethality. Mol Cell Biol, 23, 908-15.

Buontempo F, Orsini E, Martins LR, et al (2014). Cytotoxic activity of the casein kinase 2 inhibitor CX-4945 against T-cell acute lymphoblastic leukemia: targeting the unfolded protein response signaling. Leukemia, 28, 543-53.

Canton DA, Litchfield DW (2006). The shape of things to come: an emerging role for protein kinase CK2 in the regulation of cell morphology and the cytoskeleton. Cell Signal, 18, 267-75.

Channavajhala P, Seldin DC (2002). Functional interaction of protein kinase CK2 and c-Myc in lymphomagenesis. Oncogene, 21, 5280-8.

Chou ST, Patil R, Galstyan A, et al (2016). Simultaneous blockade of interacting CK2 and EGFR pathways by tumor-targeting nanobioconjugates increases therapeutic efficacy against glioblastoma multiforme. J Control Release, 244, 14-23.

Cozza G, Mazzorana M, Papinutto E, et al (2009). Quinalizarin as a potent, selective and cell-permeable inhibitor of protein kinase CK2. Biochem J, 421, 387-95.

Crawford AD, Liekens S, Kamuhabwa AR, et al (2011). Zebrafish bioassay-guided natural product discovery: isolation of angiogenesis inhibitors from East African medicinal plants. PLoS One, 6, e14694.

Daniotti JL, Allende ML, Weinberg ES, et al (1994). Cloning and expression of genes coding for protein kinase CK2 alpha and beta subunits in zebrafish (Danio rerio). Cell Mol Biol Res, 40, 431-9.

Daya-Makin M, Sanghera JS, Mogentale TL, et al (1994). Activation of a tumor-associated protein kinase (p40TAK) and casein kinase 2 in human squamous cell carcinomas and adenocarcinomas of the lung. Cancer Res, 54, 2262-8.

Di Maira G, Salvi M, Arrigoni G, et al (2005). Protein kinase CK2 phosphorylates and upregulates Akt/PKB. Cell Death Differ, 12, 668-77.

Dixit D, Sharma V, Ghosh S, et al (2012). Inhibition of Casein kinase-2 induces p53-dependent cell cycle arrest and sensitizes glioblastoma cells to tumor necrosis factor (TNFalpha)-induced apoptosis through SIRT1 inhibition. Cell Death Dis, 3, e271.

Dominguez I, Mizuno J, Wu H, et al (2005). A role for CK2alpha/ beta in Xenopus early embryonic development. Mol Cell Biochem, 274, 125-31.

Dominguez I, Mizuno J, Wu H, et al (2004). Protein kinase CK2 is required for dorsal axis formation in Xenopus embryos. Dev Biol, 274, 110-24.

Dominguez I, Sonenshein GE, Seldin DC (2009). Protein kinase CK2 in health and disease: CK2 and its role in Wnt and NFkappaB signaling: linking development and cancer. Cell Mol Life Sci, 66, 1850-7.

Faust RA, Gapany M, Tristani P, et al (1996). Elevated protein kinase CK2 activity in chromatin of head and neck tumors: association with malignant transformation. Cancer Lett, 101, 31-5.

Faust RA, Tawfic S, Davis AT, et al (2000). Antisense oligonucleotides against protein kinase CK2-alpha inhibit 
growth of squamous cell carcinoma of the head and neck in vitro. Head Neck, 22, 341-6.

Finkielsztein A, Kelly GM (2009). Altering PI3K-Akt signalling in zebrafish embryos affects PTEN phosphorylation and gastrulation. Biol Cell, 101, 661-78, 4 p following 78.

Funfschilling U, Supplie LM, Mahad D, et al (2012). Glycolytic oligodendrocytes maintain myelin and long-term axonal integrity. Nature, 485, 517-21.

Gapany M, Faust RA, Tawfic S, et al (1995). Association of elevated protein kinase CK2 activity with aggressive behavior of squamous cell carcinoma of the head and neck. Mol Med, 1, 659-66.

Giroux V, Iovanna JL, Garcia S, et al (2009). Combined inhibition of PAK7, MAP3K7 and CK2alpha kinases inhibits the growth of $\mathrm{MiaPaCa} 2$ pancreatic cancer cell xenografts. Cancer Gene Ther, 16, 731-40.

Gomes AM, Soares MV, Ribeiro P, et al (2014). Adult B-cell acute lymphoblastic leukemia cells display decreased PTEN activity and constitutive hyperactivation of PI3K/Akt pathway despite high PTEN protein levels. Haematologica, 99, 1062-8.

Gotz C, Gratz A, Kucklaender U, et al (2012). TF-a novel cell-permeable and selective inhibitor of human protein kinase CK2 induces apoptosis in the prostate cancer cell line LNCaP. Biochim Biophys Acta, 1820, 970-7.

Gowda C, Sachdev M, Muthusami S, et al (2017). Casein Kinase II (CK2) as a Therapeutic Target for Hematological Malignancies. Curr Pharm Des, 23, 95-107.

Gray GK, McFarland BC, Rowse AL, et al (2014). Therapeutic CK2 inhibition attenuates diverse prosurvival signaling cascades and decreases cell viability in human breast cancer cells. Oncotarget, 5, 6484-96.

Guerra B, Hochscherf J, Jensen NB, et al (2015). Identification of a novel potent, selective and cell permeable inhibitor of protein kinase CK2 from the NIH/NCI Diversity Set Library. Mol Cell Biochem, 406, 151-61.

Hagiwara M, Inoue S, Tanaka T, et al (1988). Differential effects of flavonoids as inhibitors of tyrosine protein kinases and serine/threonine protein kinases. Biochem Pharmacol, 37, 2987-92.

Hamacher R, Saur D, Fritsch R, et al (2007). Casein kinase II inhibition induces apoptosis in pancreatic cancer cells. Oncol Rep, 18, 695-701.

Heriche JK, Chambaz EM (1998). Protein kinase CK2alpha is a target for the Abl and Bcr-Abl tyrosine kinases. Oncogene, 17, 13-8.

Hessenauer A, Schneider CC, Gotz C, et al (2011). CK2 inhibition induces apoptosis via the ER stress response. Cell Signal, 23, 145-51.

Hung MS, Lin YC, Mao JH, et al (2010). Functional polymorphism of the CK2alpha intronless gene plays oncogenic roles in lung cancer. PLoS One, 5, e11418.

Hung MS, Xu Z, Chen Y, et al (2013). Hematein, a casein kinase II inhibitor, inhibits lung cancer tumor growth in a murine xenograft model. Int J Oncol, 43, 1517-22.

Hung MS, Xu Z, Lin YC, et al (2009). Identification of hematein as a novel inhibitor of protein kinase CK2 from a natural product library. BMC Cancer, 9, 135.

Izeradjene K, Douglas L, Delaney A, et al (2005). Casein kinase II (CK2) enhances death-inducing signaling complex (DISC) activity in TRAIL-induced apoptosis in human colon carcinoma cell lines. Oncogene, 24, 2050-8.

Jia H, Liu Y, Xia R, et al (2010). Casein kinase 2 promotes Hedgehog signaling by regulating both smoothened and Cubitus interruptus. J Biol Chem, 285, 37218-26.

Kim HR, Kim K, Lee KH, et al (2008). Inhibition of casein kinase 2 enhances the death ligand- and natural kiler cell-induced hepatocellular carcinoma cell death. Clin Exp Immunol, 152, 336-44.

Kim JS, Eom JI, Cheong JW, et al (2007). Protein kinase CK2alpha as an unfavorable prognostic marker and novel therapeutic target in acute myeloid leukemia. Clin Cancer Res, 13, 1019-28.

Kramerov AA, Saghizadeh M, Caballero S, et al (2008). Inhibition of protein kinase CK2 suppresses angiogenesis and hematopoietic stem cell recruitment to retinal neovascularization sites. Mol Cell Biochem, 316, 177-86.

Kren BT, Unger GM, Abedin MJ, et al (2015). Preclinical evaluation of cyclin dependent kinase 11 and casein kinase 2 survival kinases as RNA interference targets for triple negative breast cancer therapy. Breast Cancer Res, 17, 19.

Ku MJ, Park JW, Ryu BJ, et al (2013). CK2 inhibitor CX4945 induces sequential inactivation of proteins in the signaling pathways related with cell migration and suppresses metastasis of A549 human lung cancer cells. Bioorg Med Chem Lett, 23, 5609-13.

Lee YS, Lee DY, Yu DY, et al (2014). Helicobacter pylori induces cell migration and invasion through casein kinase 2 in gastric epithelial cells. Helicobacter, 19, 465-75.

Lin KY, Fang CL, Chen Y, et al (2010). Overexpression of nuclear protein kinase CK2 Beta subunit and prognosis in human gastric carcinoma. Ann Surg Oncol, 17, 1695-702.

Lin YC, Hung MS, Lin CK, et al (2011). CK2 inhibitors enhance the radiosensitivity of human non-small cell lung cancer cells through inhibition of stat3 activation. Cancer Biother Radiopharm, 26, 381-8.

Litchfield DW (2003). Protein kinase CK2: structure, regulation and role in cellular decisions of life and death. Biochem $J$, 369, $1-15$.

Liu J, Cao XC, Xiao Q, et al (2015). Apigenin inhibits HeLa sphere-forming cells through inactivation of casein kinase 2alpha. Mol Med Rep, 11, 665-9.

Lou DY, Dominguez I, Toselli P, et al (2008). The alpha catalytic subunit of protein kinase CK2 is required for mouse embryonic development. Mol Cell Biol, 28, 131-9.

Mandal T, Bhowmik A, Chatterjee A, et al (2014). Reduced phosphorylation of Stat 3 at Ser-727 mediated by casein kinase 2 - protein phosphatase 2A enhances Stat3 Tyr-705 induced tumorigenic potential of glioma cells. Cell Signal, 26, 1725-34.

Manni S, Brancalion A, Mandato E, et al (2013). Protein kinase CK2 inhibition down modulates the NF-kappaB and STAT3 survival pathways, enhances the cellular proteotoxic stress and synergistically boosts the cytotoxic effect of bortezomib on multiple myeloma and mantle cell lymphoma cells. PLoS One, 8, e75280.

Martins LR, Lucio P, Melao A, et al (2014). Activity of the clinical-stage CK2-specific inhibitor CX-4945 against chronic lymphocytic leukemia. Leukemia, 28, 179-82.

Martins LR, Lucio P, Silva MC, et al (2010). Targeting CK2 overexpression and hyperactivation as a novel therapeutic tool in chronic lymphocytic leukemia. Blood, 116, 2724-31.

Meggio F, Pinna LA (2003). One-thousand-and-one substrates of protein kinase CK2?. Faseb J, 17, 349-68.

Mestres P, Boldyreff B, Ebensperger C, et al (1994). Expression of casein kinase 2 during mouse embryogenesis. Acta Anat (Basel), 149, 13-20.

Miller SJ, Lou DY, Seldin DC, et al (2002). Direct identification of PTEN phosphorylation sites. FEBS Lett, 528, 145-53.

Montenarh M (2014). Protein kinase CK2 and angiogenesis. $A d v$ Clin Exp Med, 23, 153-8.

Moucadel V, Prudent R, Sautel CF, et al (2011). Antitumoral activity of allosteric inhibitors of protein kinase CK2. Oncotarget, 2, 997-1010. 
Nitta RT, Gholamin S, Feroze AH, et al (2015). Casein kinase 2alpha regulates glioblastoma brain tumor-initiating cell growth through the beta-catenin pathway. Oncogene, 34, 3688-99.

Olsen BB, Issinger OG, Guerra B (2010). Regulation of DNA-dependent protein kinase by protein kinase CK2 in human glioblastoma cells. Oncogene, 29, 6016-26.

Ortega CE, Seidner Y, Dominguez I (2014). Mining CK2 in cancer. PLoS One, 9, e115609.

P Oc, Rusch V, Talbot SG, et al (2004). Casein kinase II alpha subunit and $\mathrm{C} 1$-inhibitor are independent predictors of outcome in patients with squamous cell carcinoma of the lung. Clin Cancer Res, 10, 5792-803.

Pagano MA, Meggio F, Ruzzene M, et al (2004). 2-Dimethylamino-4,5,6,7- tetrabromo- $1 \mathrm{H}$ - benzimidazole: a novel powerful and selective inhibitor of protein kinase CK2. Biochem Biophys Res Commun, 321, 1040-4.

Pagano MA, Poletto G, Di Maira G, et al (2007). Tetrabromocinnamic acid (TBCA) and related compounds represent a new class of specific protein kinase CK2 inhibitors. Chembiochem, 8, 129-39.

Park JH, Kim JJ, Bae YS (2013). Involvement of PI3K-AKTmTOR pathway in protein kinase CKII inhibition-mediated senescence in human colon cancer cells. Biochem Biophys Res Commun, 433, 420-5.

Pathak HB, Zhou Y, Sethi G, et al (2015). A synthetic lethality screen using a focused siRNA library to Identify sensitizers to dasatinib therapy for the treatment of epithelial ovarian cancer. PLoS One, 10, e 0144126.

Perea SE, Reyes O, Baladron I, et al (2008). CIGB-300, a novel proapoptotic peptide that impairs the CK2 phosphorylation and exhibits anticancer properties both in vitro and in vivo. Mol Cell Biochem, 316, 163-7.

Perera Y,Toro ND, Gorovaya L, et al (2014). Synergistic interactions of the anti-casein kinase 2 CIGB-300 peptide and chemotherapeutic agents in lung and cervical preclinical cancer models. Mol Clin Oncol, 2, 935-44.

Piazza F, Manni S, Ruzzene M, et al (2012). Protein kinase CK2 in hematologic malignancies: reliance on a pivotal cell survival regulator by oncogenic signaling pathways. Leukemia, 26, 1174-9.

Piazza F, Manni S, Semenzato G (2013). Novel players in multiple myeloma pathogenesis: role of protein kinases CK2 and GSK3. Leuk Res, 37, 221-7.

Piazza FA, Ruzzene M, Gurrieri C, et al (2006). Multiple myeloma cell survival relies on high activity of protein kinase CK2. Blood, 108, 1698-707.

Pierre F, Chua PC, O'Brien SE, et al (2011). Pre-clinical characterization of CX-4945, a potent and selective small molecule inhibitor of CK2 for the treatment of cancer. $\mathrm{Mol}$ Cell Biochem, 356, 37-43.

Pinna LA, Meggio F (1997). Protein kinase CK2 ("casein kinase-2") and its implication in cell division and proliferation. Prog Cell Cycle Res, 3, 77-97.

Pizzi M, Piazza F, Agostinelli C, et al (2015). Protein kinase CK2 is widely expressed in follicular, Burkitt and diffuse large B-cell lymphomas and propels malignant B-cell growth. Oncotarget, 6, 6544-52.

Prudent R, Moucadel V, Nguyen CH, et al (2010). Antitumor activity of pyridocarbazole and benzopyridoindole derivatives that inhibit protein kinase CK2. Cancer Res, 70, 9865-74.

Qaiser F, Trembley JH, Kren BT, et al (2014). Protein kinase CK2 inhibition induces cell death via early impact on mitochondrial function. $J$ Cell Biochem, 115, 2103-15.

Qaiser F, Trembley JH, Sadiq S, et al (2016). Examination of CK2alpha and NF-kappaB p65 expression in human benign
Protein Kinase CK2, a Potential Therapeutic Target

prostatic hyperplasia and prostate cancer tissues. $\mathrm{Mol}$ Cell Biochem, 420, 43-51.

Quotti Tubi L, Gurrieri C, Brancalion A, et al (2013). Inhibition of protein kinase CK2 with the clinical-grade small ATP-competitive compound CX-4945 or by RNA interference unveils its role in acute myeloid leukemia cell survival, p53-dependent apoptosis and daunorubicin-induced cytotoxicity. J Hematol Oncol, 6, 78.

Romieu-Mourez R, Landesman-Bollag E, Seldin DC, et al (2002). Protein kinase CK2 promotes aberrant activation of nuclear factor-kappaB, transformed phenotype, and survival of breast cancer cells. Cancer Res, 62, 6770-8.

Ruzzene M, Pinna LA (2010). Addiction to protein kinase CK2: a common denominator of diverse cancer cells? Biochim Biophys Acta, 1804, 499-504.

Sarduy MR, Garcia I, Coca MA, et al (2015). Optimizing CIGB-300 intralesional delivery in locally advanced cervical cancer. Br J Cancer, 112, 1636-43.

Sarno S, Reddy H, Meggio F, et al (2001). Selectivity of 4,5,6,7-tetrabromobenzotriazole, an ATP site-directed inhibitor of protein kinase CK2 ('casein kinase-2'). FEBS Lett, 496, 44-8.

Sass G, Klinger N, Sirma H, et al (2011). Inhibition of experimental HCC growth in mice by use of the kinase inhibitor DMAT. Int J Oncol, 39, 433-42.

Schneider CC, Hessenauer A, Gotz C, et al (2009). DMAT, an inhibitor of protein kinase CK2 induces reactive oxygen species and DNA double strand breaks. Oncol Rep, 21, 1593-7.

Schneider HR, Reichert GH, Issinger OG (1986). Enhanced casein kinase II activity during mouse embryogenesis. Identification of a $110-\mathrm{kDa}$ phosphoprotein as the major phosphorylation product in mouse embryos and Krebs II mouse ascites tumor cells. Eur J Biochem, 161, 733-8.

Seldin DC (1995). New models of lymphoma in transgenic mice. Curr Opin Immunol, 7, 665-73.

Seldin DC, Landesman-Bollag E, Farago M, et al (2005). CK2 as a positive regulator of $\mathrm{Wnt}$ signalling and tumourigenesis. Mol Cell Biochem, 274, 63-7.

Seldin DC, Leder P (1995). Casein kinase II alpha transgeneinduced murine lymphoma: relation to theileriosis in cattle. Science, 267, 894-7.

Shimada K, Anai S, Marco DA, et al (2011). Cyclooxygenase 2-dependent and independent activation of Akt through casein kinase 2alpha contributes to human bladder cancer cell survival. BMC Urol, 11, 8.

Siddiqui-Jain A, Bliesath J, Macalino D, et al (2012). CK2 inhibitor CX-4945 suppresses DNA repair response triggered by DNA-targeted anticancer drugs and augments efficacy: mechanistic rationale for drug combination therapy. Mol Cancer Ther, 11, 994-1005.

Siddiqui-Jain A, Drygin D, Streiner N, et al (2010). CX-4945, an orally bioavailable selective inhibitor of protein kinase CK2, inhibits prosurvival and angiogenic signaling and exhibits antitumor efficacy. Cancer Res, 70, 10288-98.

Silva A, Yunes JA, Cardoso BA, et al (2008). PTEN posttranslational inactivation and hyperactivation of the PI3K/Akt pathway sustain primary $\mathrm{T}$ cell leukemia viability. J Clin Invest, 118, 3762-74.

Solares AM, Santana A, Baladron I, et al (2009). Safety and preliminary efficacy data of a novel casein kinase 2 (CK2) peptide inhibitor administered intralesionally at four dose levels in patients with cervical malignancies. BMC Cancer, 9, 146.

Song C, Gowda C, Pan X, et al (2015). Targeting casein kinase II restores Ikaros tumor suppressor activity and demonstrates therapeutic efficacy in high-risk leukemia. Blood, 126, 
1813-22.

Stalter G, Siemer S, Becht E, et al (1994). Asymmetric expression of protein kinase CK2 subunits in human kidney tumors. Biochem Biophys Res Commun, 202, 141-7.

Tang AQ, Cao XC, Tian L, et al (2015). Apigenin inhibits the self-renewal capacity of human ovarian cancer SKOV3derived sphere-forming cells. Mol Med Rep, 11, 2221-6.

Tawfic S, Yu S, Wang H, et al (2001). Protein kinase CK2 signal in neoplasia. Histol Histopathol, 16, 573-82.

Torres J, Pulido R (2001). The tumor suppressor PTEN is phosphorylated by the protein kinase $\mathrm{CK} 2$ at its $\mathrm{C}$ terminus. Implications for PTEN stability to proteasome-mediated degradation. $J$ Biol Chem, 276, 993-8.

Trembley JH, Unger GM, Gomez OC, et al (2014). Tenfibgen-DMAT nanocapsule delivers CK2 inhibitor DMAT to prostate cancer xenograft tumors causing inhibition of cell proliferation. Mol Cell Pharmacol, 6, 15-25.

Trembley JH, Unger GM, Korman VL, et al (2012). Nanoencapsulated anti-CK2 small molecule drug or siRNA specifically targets malignant cancer but not benign cells. Cancer Lett, 315, 48-58.

Unger GM, Kren BT, Korman VL, et al (2014). Mechanism and efficacy of sub-50-nm tenfibgen nanocapsules for cancer cell-directed delivery of anti-CK2 RNAi to primary and metastatic squamous cell carcinoma. Mol Cancer Ther, 13, 2018-29.

Wang G, Ahmad KA, Harris NH, et al (2008). Impact of protein kinase CK2 on inhibitor of apoptosis proteins in prostate cancer cells. Mol Cell Biochem, 316, 91-7.

Wang G, Unger G, Ahmad KA, et al (2005). Downregulation of CK2 induces apoptosis in cancer cells--a potential approach to cancer therapy. Mol Cell Biochem, 274, 77-84.

Wang H, Davis A, Yu S, et al (2001). Response of cancer cells to molecular interruption of the CK2 signal. Mol Cell Biochem, 227, 167-74.

Wirkner U, Voss H, Lichter P, et al (1992). Human casein kinase II subunit alpha: sequence of a processed (pseudo)gene and its localization on chromosome 11. Biochim Biophys Acta, 1131, 220-2.

Wu D, Sui C, Meng F, et al (2014). Stable knockdown of protein kinase CK2-alpha (CK2alpha) inhibits migration and invasion and induces inactivation of hedgehog signaling pathway in hepatocellular carcinoma Hep G2 cells. Acta Histochem, 116, 1501-8.

Xu W, Chen Q, Wang Q, et al (2014). JWA reverses cisplatin resistance via the $\mathrm{CK} 2-\mathrm{XRCC} 1$ pathway in human gastric cancer cells. Cell Death Dis, 5, e1551.

Xu X, Landesman-Bollag E, Channavajhala PL, et al (1999a). Murine protein kinase CK2: gene and oncogene. Mol Cell Biochem, 191, 65-74.

Xu X, Toselli PA, Russell LD, et al (1999b). Globozoospermia in mice lacking the casein kinase II alpha' catalytic subunit. Nat Genet, 23, 118-21.

Yao K, Youn H, Gao X, et al (2012). Casein kinase 2 inhibition attenuates androgen receptor function and cell proliferation in prostate cancer cells. Prostate, 72, 1423-30.

Yaylim I, Isbir T (2002). Enhanced casein kinase II (CK II) activity in human lung tumours. Anticancer Res, 22, 215-8.

Yde CW, Frogne T, Lykkesfeldt AE, et al (2007). Induction of cell death in antiestrogen resistant human breast cancer cells by the protein kinase CK2 inhibitor DMAT. Cancer Lett, 256, 229-37.

Yim H, Lee YH, Lee CH, et al (1999). Emodin, an anthraquinone derivative isolated from the rhizomes of Rheum palmatum, selectively inhibits the activity of casein kinase II as a competitive inhibitor. Planta Med, 65, 9-13.
Yoo JY, Choi HK, Choi KC, et al (2012). Nuclear hormone receptor corepressor promotes esophageal cancer cell invasion by transcriptional repression of interferon-gammainducible protein 10 in a casein kinase 2-dependent manner. Mol Biol Cell, 23, 2943-54.

Zandomeni R, Zandomeni MC, Shugar D, et al (1986). Casein kinase type II is involved in the inhibition by 5,6-dichloro1-beta-D-ribofuranosylbenzimidazole of specific RNA polymerase II transcription. J Biol Chem, 261, 3414-9.

Zhang C, Vilk G, Canton DA, et al (2002). Phosphorylation regulates the stability of the regulatory CK2beta subunit. Oncogene, 21, 3754-64.

Zhang HX, Jiang SS, Zhang XF, et al (2015). Protein kinase CK2alpha catalytic subunit is overexpressed and serves as an unfavorable prognostic marker in primary hepatocellular carcinoma. Oncotarget, 6, 34800-17.

Zhao M, Ma J, Zhu HY, et al (2011). Apigenin inhibits proliferation and induces apoptosis in human multiple myeloma cells through targeting the trinity of CK2, Cdc37 and Hsp90. Mol Cancer, 10, 104.

Zheng Y, McFarland BC, Drygin D, et al (2013). Targeting protein kinase CK2 suppresses prosurvival signaling pathways and growth of glioblastoma. Clin Cancer Res, 19, 6484-94.

Zheng Y, Qin H, Frank SJ, et al (2011). A CK2-dependent mechanism for activation of the JAK-STAT signaling pathway. Blood, 118, 156-66.

Zhou B, Ritt DA, Morrison DK, et al (2016). Protein kinase CK2alpha maintains extracellular signal-regulated kinase (ERK) activity in a CK2alpha kinase-independent manner to promote resistance to inhibitors of RAF and MEK but not ERK in BRAF Mutant Melanoma. J Biol Chem, 291, 17804-15.

Zhou F, Xu J, Ding G, et al (2014). Overexpressions of CK2beta and XIAP are associated with poor prognosis of patients with cholangiocarcinoma. Pathol Oncol Res, 20, 73-9.

Zhou Y, Li K, Zhang S, et al (2015). Quinalizarin, a specific CK2 inhibitor, reduces cell viability and suppresses migration and accelerates apoptosis in different human lung cancer cell lines. Indian J Cancer, 52, e119-24.

Zou J, Luo H, Zeng Q, et al (2011). Protein kinase CK2alpha is overexpressed in colorectal cancer and modulates cell proliferation and invasion via regulating EMT-related genes. J Transl Med, 9, 97.

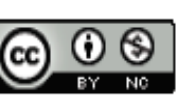

This work is licensed under a Creative Commons AttributionNon Commercial 4.0 International License. 